\title{
Climate change and forests in the Congo Basin Synergy between adaptation and mitigation
}

\section{Background}

Two main types of strategies are available to deal with climate change: mitigation and adaptation. Mitigation addresses underlying causes by reducing the accumulation of greenhouse gases in the atmosphere. Adaptation addresses the effects by helping people and ecosystems cope with climate change.

Forests contribute to mitigation by storing carbon, hence reducing deforestation reduction is one mitigation strategy. Forests also help people in their adaptation efforts by, for example, regulating rivers or by supplying important products to communities where agriculture and livestock production have been distressed by climate.

Adaptation is gaining ground in the international arena; projects and national policies are emerging at a slower pace in developing countries. Furthermore, forests and forest populations are given little attention in national debates and policies on adaptation, and the Congo Basin has limited experience in reducing emissions caused by deforestation and forest degradation (REDD+). Lastly, although the forest sector is known to offer opportunities for developing synergies between adaptation and mitigation, few models exist and very little knowledge can confirm these opportunities.

\section{Project description}

To make up for these shortcomings, in 2010, the Centre for International Forestry Research (CIFOR) launched the project Climate Change and Forests in the Congo Basin: Synergies between Adaptation and Mitigation (COBAM).

COBAM is a 5-year project that will be carried out in 6 countries of Central Africa and 3 PACEBCo landscapes (see Figure 1). COBAM is funded by the African Development Bank (AfDB) as part of its support for the Economic Community of Central African States (CEEAC) for implementing the Congo Basin Ecosystems Conservation Support Programme (PACEBCO)

\section{Objectives}

The overall objective of the project is to develop an appropriate reaction to vulnerability stemming from climate change in Congo Basin landscapes. The brief is to provide decision makers, practitioners and local communities with the information, analyses and tools needed to design and implement policies and projects for climate change adaptation and the reduction of carbon emissions in the forests, with equitable impacts and co-benefits on poverty reduction, the improvement of ecosystem services other than carbon, and the protection of livelihoods, traditional practices and local rights.

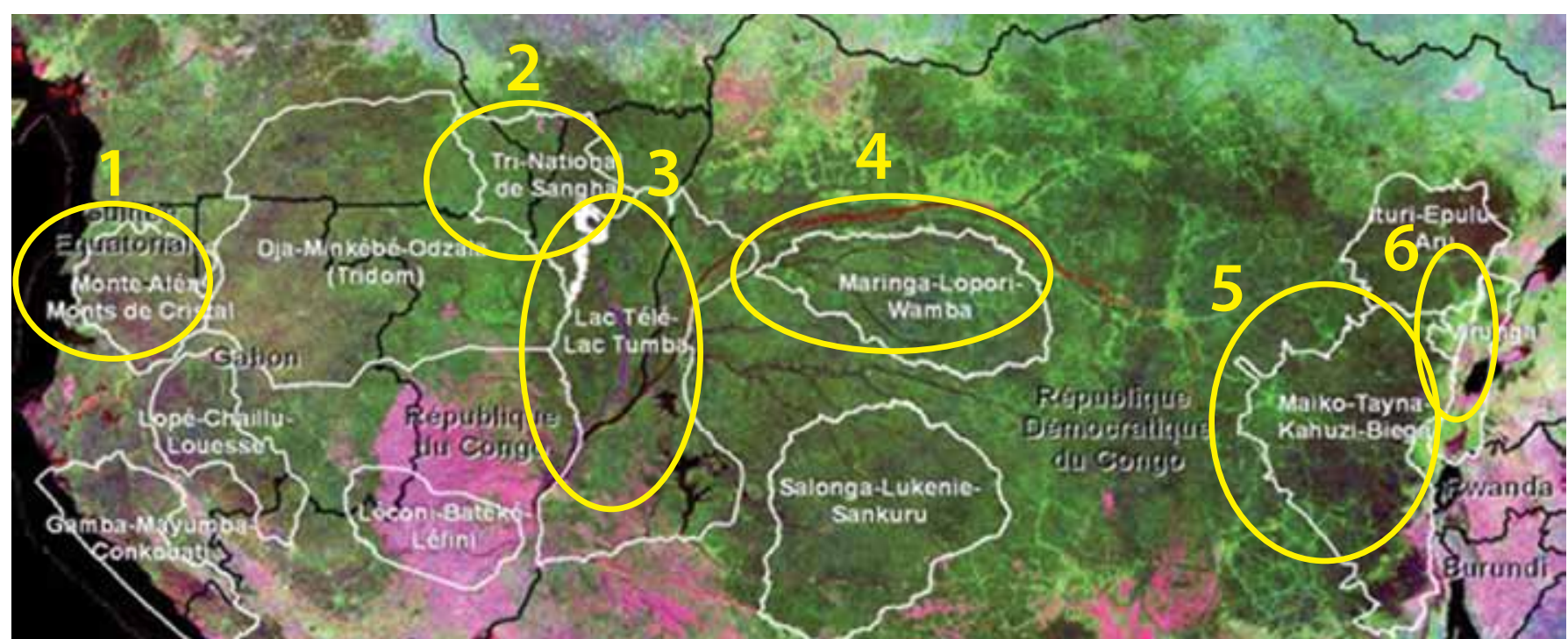

Figure 1. The six landscapes of the Congo Basin Ecosystems Conservation Support Programme

Source: Central African Regional Program for the Environment 


\section{Components of COBAM}

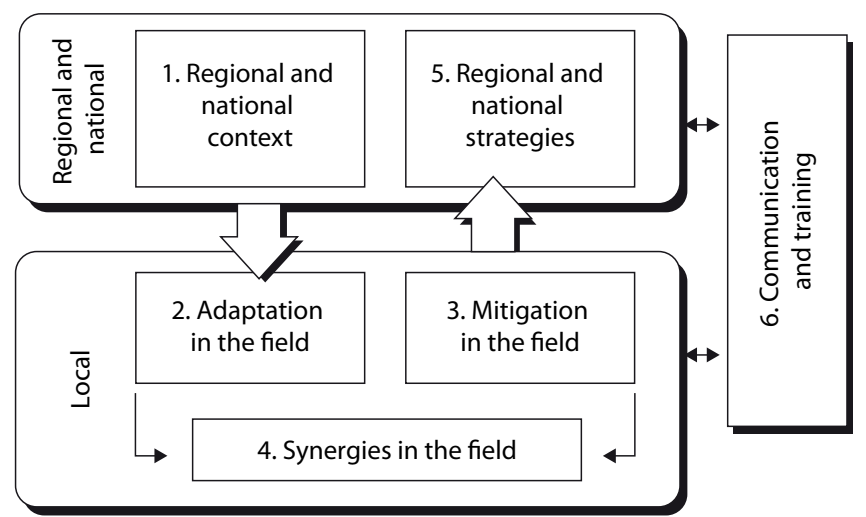

Figure 2. COBAM organisation

The specific objectives are to:

1. help local populations define and implement their own local adaptation measures and REDD+ projects, based on an analysis of regional and national forests and climate change policies;

2. analyse the level of vulnerability of local communities and define adaptation in selected locations;

3. analyse the opportunities for REDD+, aspects of governance and the potential impacts on local practices;

4. recommend approaches to defining local projects that strengthen synergies between mitigation and adaptation, and to identifying and mobilising partnerships in project implementation;

5. develop national and regional strategies that include adaptation measures and REDD+ in forest policies and promote synergies between adaptation and mitigation;

6. communicate, share knowledge and build capacity at local, subnational and national levels regarding adaptation and REDD+ in the forests of the Congo Basin.

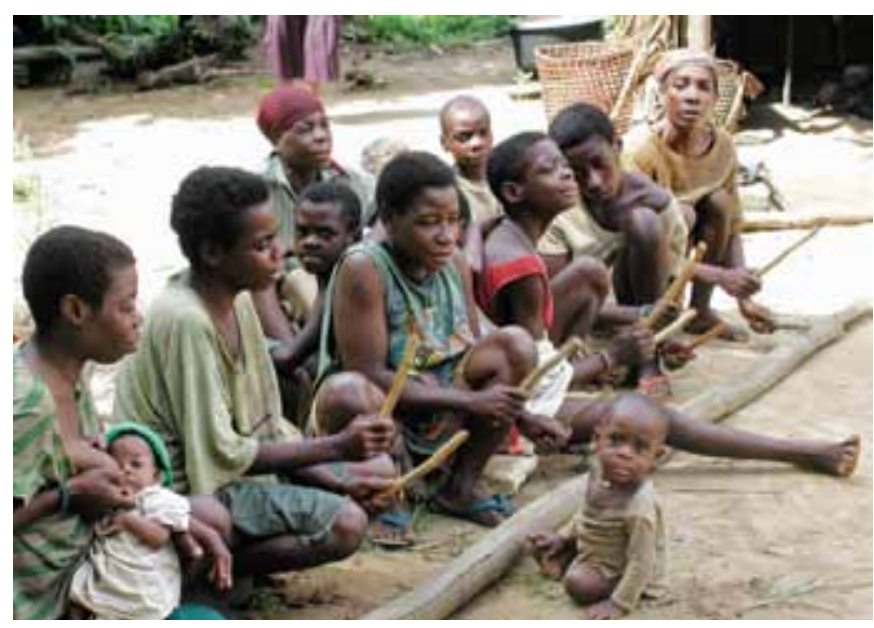

The traditional life of BaAka pygmies in Central Africa Republic is threatened by deforestation. Photo courtesy Marie Claude Simard

\section{COBAM partnerships}

Besides CIFOR, the COBAM project will work with several partners including:

- research centres and national universities in Central Africa;

- international partners including CIRAD, SEl, UEA and IRD;

- regional organisations including COMIFAC, AfDB, CEEAC, CARPE, and CBFP;

- NGOs working at the selected sites;

- other CIFOR projects active in the area including CoFCCA, GCS-REDD+ and FORAFAMA.

\section{www.cifor.org/cobam}

\section{Contacts}

Anne Marie Tiani: a.tiani@cgiar.org

Bele Youssoufa : b.youssoufa@cgiar.org

CIFOR's Central Africa Regional Office: cifor.cameroon@cgiar.org
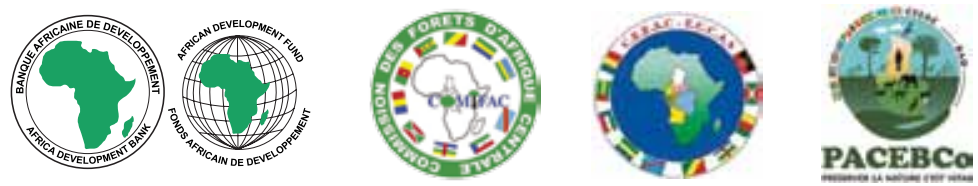
policies and practices that affect forests in developing countries. CIFOR is one of 15 centres within the Consultative Group on International Agricultural Research (CGIAR). CIFOR's headquarters are in Bogor, Indonesia. It also has offices in Asia, Africa and South America. 